\title{
Ga2O3 field-effect-transistor-based solar-blind photodetector with fast response and high photo-to-dark current ratio
}

DOI:

10.1109/LED.2018.2872017

\section{Document Version}

Accepted author manuscript

Link to publication record in Manchester Research Explorer

Citation for published version (APA):

Liu, Y., Du, L., Liang, G., Mu, W., Jia, Z., Xu, M., Xin, Q., Tao, X., \& Song, A. (2018). Ga $\mathrm{O}_{3}$ field-effect-transistorbased solar-blind photodetector with fast response and high photo-to-dark current ratio. ${ }_{E} E_{E} E$ Electron Device Letters. https://doi.org/10.1109/LED.2018.2872017

\section{Published in:}

IEEE Electron Device Letters

\section{Citing this paper}

Please note that where the full-text provided on Manchester Research Explorer is the Author Accepted Manuscript or Proof version this may differ from the final Published version. If citing, it is advised that you check and use the publisher's definitive version.

\section{General rights}

Copyright and moral rights for the publications made accessible in the Research Explorer are retained by the authors and/or other copyright owners and it is a condition of accessing publications that users recognise and abide by the legal requirements associated with these rights.

\section{Takedown policy}

If you believe that this document breaches copyright please refer to the University of Manchester's Takedown Procedures [http://man.ac.uk/04Y6Bo] or contact uml.scholarlycommunications@manchester.ac.uk providing relevant details, so we can investigate your claim.

\section{OPEN ACCESS}




\title{
$\mathrm{Ga}_{2} \mathrm{O}_{3}$ field-effect-transistor-based solar-blind photodetector with fast response and high photo-to-dark current ratio
}

\author{
Yaxuan Liu, Lulu Du, Guangda Liang, Wenxiang Mu, Zhitai Jia, Mingsheng Xu, Qian Xin, Xutang \\ Tao, and Aimin Song, Senior Member, IEEE
}

\begin{abstract}
A high performance solar-blind photodetector based on Cr-doped gallium oxide $\left(\mathrm{Ga}_{2} \mathrm{O}_{3}\right)$ has been fabricated. A 140nm-thick $\mathrm{Ga}_{2} \mathrm{O}_{3}$ layer was mechanically exfoliated from bulk crystal. The photodetector was based on a field effect transistor structure, which showed a very high photo-to-dark current ratio larger than $10^{6}$ and excellent current saturation. When the photodetector was tested with a $254 \mathrm{~nm}$ ultra-violet light, the ratio of drain current with and without the UV light reached nearly six orders of magnitude. The dark current was as low as 5 pA. Furthermore, the current rise time and decay time were both about $25 \mathrm{~ms}$. High responsivity of $4.79 \times 10^{5} \mathrm{~A} / \mathrm{W}$ and external quantum efficiency of $2.34 \times 10^{6}$ also have been achieved at the same time.
\end{abstract}

Index Terms - gallium oxide $\left(\mathrm{Ga}_{2} \mathrm{O}_{3}\right)$, filed-effect-transistor (FET), solar-blind photodetector

\section{INTRODUCTION}

$\mathrm{B}$ ECAUSE of the absence of radiation in the solar-blind region (240-280 nm) at the surface of the Earth, the so-called solar-blind photodetectors have advantages of high signal-tonoise ratios, low false alarm rates and ability of weak signal detection in many applications including ozone monitoring, flame detection, and missile tracking[1]-[5]. In recent years, a large variety of semiconductors like $\mathrm{Al}_{\mathrm{x}} \mathrm{Ga}_{1-\mathrm{x}} \mathrm{N}, \mathrm{Zn}_{\mathrm{x}} \mathrm{Mg}_{1-\mathrm{x}} \mathrm{O}$, and $\mathrm{Zn}_{\mathrm{x}} \mathrm{Ga}{ }_{1-\mathrm{x}} \mathrm{O}$ have been explored for solar-blind photodetectors $[6,7]$. However, their complex growth processes and difficulties in achieving high material quality are still challenging.

The direct-band and wide-band gap $(4.9 \mathrm{eV})$ of gallium oxide $\left(\mathrm{Ga}_{2} \mathrm{O}_{3}\right)$ is ideal for solar-blind light sensing. Furthermore, the crystal growth of $\mathrm{Ga}_{2} \mathrm{O}_{3}$ bulk single crystals and the material quality have progressed rapidly in recent years $[8,9]$. Compared with previous multi-element alloy materials [6, 7], $\mathrm{Ga}_{2} \mathrm{O}_{3}$ is not an alloy, and hence has a lower defect density which is critical to achieve a low dark current [10]. $\mathrm{Ga}_{2} \mathrm{O}_{3}$ active layers in

This work was supported by the National Key Research and Development Program of China (Grant No. 2016YFA0301200 and 2016 YFA0201800), Engineering and Physical Sciences Research Council (EPSRC) (Grant No. EP/N021258/1), the Natural Science Foundation of China(61504044), the Natural Science Foundation of Shandong Province (ZR201709260014), the Key Research and Development Program of Shandong Province (2017GGX10111, 2017GGX10121 and 2018GGX101027), China Postdoctoral Science Foundation funded project (2016M590634), and the Fundamental Research Funds of Shandong University (2016WLJH44 and 2017TB0021). (Corresponding author: Mingsheng Xu; Qian Xin; Xutang Tao) photodetectors have already been achieved via several methods, including hot-wall chemical vapor deposition [2], metalorganic vapor phase epitaxy [11], molecular beam epitaxy [12], magnetron sputtering $[13,14]$, and mechanical exfoliation from bulk single crystals $[15,16]$. Among these methods, mechanical exfoliation ensures the highest film quality, and thus is highly beneficial for low defect density, low dark current, and high response to UV light [17]. $\mathrm{Ga}_{2} \mathrm{O}_{3}$ single crystals are layered materials, and there are two different Ga sites and two cleavage planes [(100) and (001)] [18]. Owing to such a cleavage nature, which is somewhat similar to two-dimensional materials, high quality $\mathrm{Ga}_{2} \mathrm{O}_{3}$ single crystalline films can be obtained by mechanical exfoliation from the bulk crystal [19].

Different types of photodetectors based on $\mathrm{Ga}_{2} \mathrm{O}_{3}$ have been demonstrated. This includes metal-semiconductor-metal structures[15,17], Schottky barrier diodes [21], diamond/ $\mathrm{Ga}_{2} \mathrm{O}_{3}$ heterojunctions [4], and graphene $/ \mathrm{Ga}_{2} \mathrm{O}_{3} /$ graphene hybrid structures [22]. Field-effect-transistors (FETs) are also often used as photodetectors due to their abilities of controlling the off current by gate bias. As a result, FET photodetectors can achieve very high photo-to-dark current ratio $\left(I_{\text {photo }} / I_{\text {dark }}\right)$ and low dark current [23]. However, very few $\mathrm{Ga}_{2} \mathrm{O}_{3}$ solar-blind photodetectors with an FET structure have been reported, and their response speed still need to be further improved to meet the requirement of real applications [17].

In this work, we fabricated FET solar-blind photodetectors based on high quality $\mathrm{Ga}_{2} \mathrm{O}_{3}$ flake with a thickness of $142 \mathrm{~nm}$, exfoliated from a Cr-doped $\mathrm{Ga}_{2} \mathrm{O}_{3}$ single crystal. It is reported that $\mathrm{Cr}$ dopant has advantage of modification optical properties of $\mathrm{Ga}_{2} \mathrm{O}_{3}$ [24]. The high crystal quality and the thin flake thickness contribute to the high performance of the photodetector which shows the current response time of about $25 \mathrm{~ms}, I_{\text {photo }} / I_{\text {dark }}$ of $8 \times 10^{5}$, and responsivity of $4.79 \times 10^{5} \mathrm{~A} / \mathrm{W}$.

Y. Liu, L. Du, G. Liang, M. Xu, Q. Xin, A. Song are with the Center of Nanoelectronics, and School of Microelectronics, Shandong University, Jinan 250100, P. R. China. (e-mail: xums@sdu.edu.cn; xinq@sdu.edu.cn)

Y. Liu, L. Du, G. Liang, W. Mu, Z. Jia, M. Xu, Q. Xin, X. Tao, A. Song are with the State Key Laboratory of Crystal Materials, Shandong University, Jinan 250100, P. R. China. (e-mail: txt@sdu.edu.cn)

A. Song is with School of Electrical and Electronic Engineering, University of Manchester, Manchester M13 9PL, United Kingdom. (e-mail: a.song@manchester.ac.uk) 


\section{Devices Fabrication And Measurement}

The schematic structure of $\mathrm{Ga}_{2} \mathrm{O}_{3}$-based FET photodetector is shown in Fig. 1(a). Figure 1(b) shows the top view scanning electron microscopy (SEM, FEI Nano 450) image of the device. The thickness of $\mathrm{Ga}_{2} \mathrm{O}_{3}$ channel layer in FET is $142 \mathrm{~nm}$, as revealed by atomic force microscopy (AFM, Benyuan CSPM5500) and shown in Fig. 1(c). The $\mathrm{Ga}_{2} \mathrm{O}_{3}$ film was prepared by mechanically exfoliation from $\mathrm{Cr}$-doped $\beta-\mathrm{Ga}_{2} \mathrm{O}_{3}$ single crystals wafer $(5 \mathrm{~mm} \times 10 \mathrm{~mm} \times 5 \mathrm{~mm})$ grown by edgedefined film-fed growth (EFG) method [9]. The electron carrier concentration in the $\mathrm{Ga}_{2} \mathrm{O}_{3}$ wafer is $\sim 1.0 \times 10^{18} \mathrm{~cm}^{-3}$ according to the Hall measurement. After exfoliation, the $\mathrm{Ga}_{2} \mathrm{O}_{3}$ flakes were then transferred quickly to a heavily $\mathrm{p}^{+}$-doped $\mathrm{Si}$ wafer, with a 100 -nm-thick thermally grown $\mathrm{SiO}_{2}$ as the gate dielectric. To enhance the adhesion between $\mathrm{Ga}_{2} \mathrm{O}_{3}$ and $\mathrm{Si}$ substrate and reduce contaminants, the $\mathrm{Si}$ substrate was pretreated by oxygen plasma (ProCleanerTM) for 3 minutes. $\mathrm{Ti} / \mathrm{Au}(20 / 100 \mathrm{~nm})$ as the source and drain electrodes were defined on both ends of the $\mathrm{Ga}_{2} \mathrm{O}_{3}$ flakes by photolithography, electron-beam evaporation, and lift-off. The source and drain contacts were improved by an inductive coupled plasma etch before electrodes deposition with the power, chamber pressure, gas flow, and etching time of $150 \mathrm{~W}, 20 \mathrm{mTorr}, \mathrm{BCl}_{3} / \mathrm{Ar}(15$ $\mathrm{sccm} / 5 \mathrm{sccm}$ ) and 2 minutes, respectively. The channel length and width are 24 and $13 \mu \mathrm{m}$, respectively.

(a)

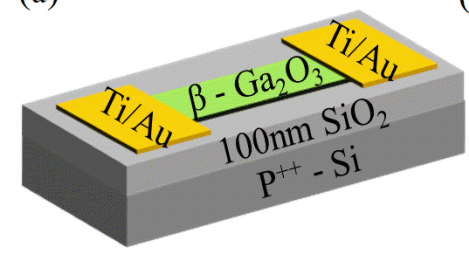

(b)
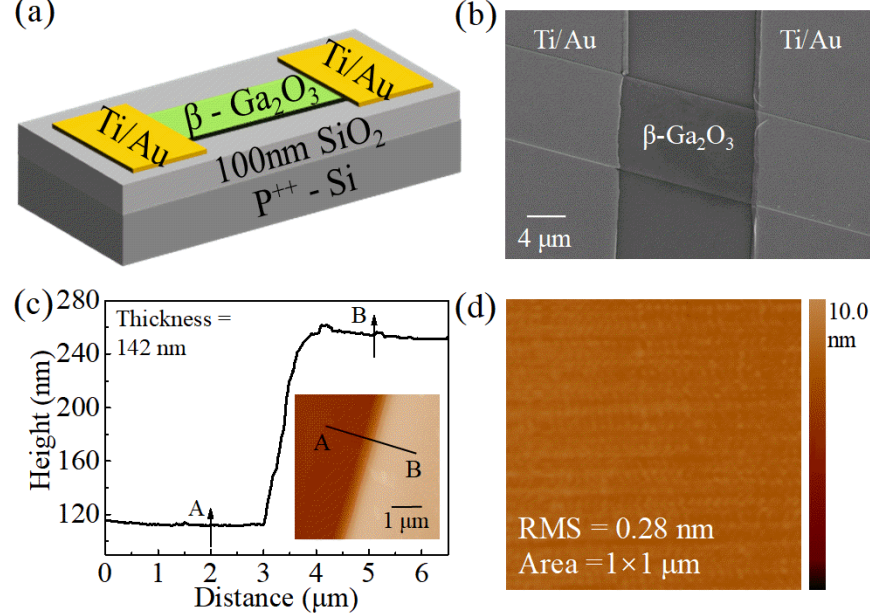

(d)

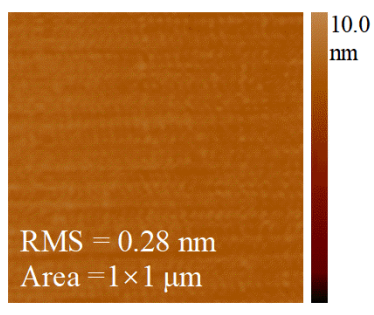

Fig. 1. (a) Schematic of the $\mathrm{Ga}_{2} \mathrm{O}_{3}$ FET, (b) SEM top view of the FET, (c) AFM height profile of the exfoliated $\mathrm{Ga}_{2} \mathrm{O}_{3}$, (d) AFM image of the $\mathrm{Ga}_{2} \mathrm{O}_{3}$ surface.

A source/measure unit semiconductor parameter analyzer (Keysight B2902A) was used to measure the electrical properties and time-dependent photo response of the device at room temperature. A $5.3 \mu \mathrm{W} / \mathrm{cm}^{2}$ deep ultraviolet lamp with emission wavelength of $254 \mathrm{~nm}$ (UVCN, 10-04000) was used for solar-blind detection measurements.

\section{Results AND Discussions}

The exfoliated $\mathrm{Ga}_{2} \mathrm{O}_{3}$ flake has an ultra-smooth and uniform surface with a root mean square roughness of $0.28 \mathrm{~nm}$, revealed by AFM, as shown in Fig. 1(d), indicating a high film surface quality. Figure 2(a) shows the X-ray diffraction spectra of the $\mathrm{Ga}_{2} \mathrm{O}_{3}$ wafer, illustrating the crystalline structure of the sample. The UV-visible optical transmittance spectra of the $\mathrm{Ga}_{2} \mathrm{O}_{3}$ wafer is shown in Fig. 2(b). The transmittance declines abruptly when the photon wavelength decreases from 360 to $260 \mathrm{~nm}$ and is close to zero when the wavelength is lower than $260 \mathrm{~nm}$. By a standard fitting, the bandgap of the sample is estimated to be $4.72 \mathrm{eV}$, as shown in inset of Fig. 2(b). These results demonstrate that our $\mathrm{Ga}_{2} \mathrm{O}_{3}$ single crystal has an outstanding crystallization quality and good response to the deep UV light.

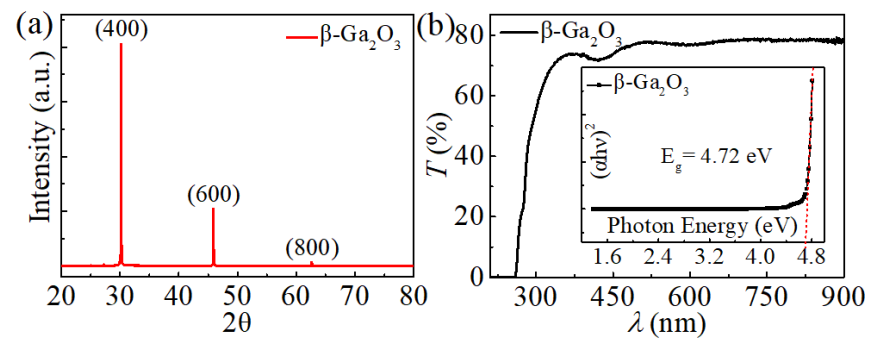

Fig. 2. X-ray diffraction scan (a) and transmittance spectrum (b) of the $\mathrm{Ga}_{2} \mathrm{O}_{3}$ crystal. Inset shows the bandgap of the $\mathrm{Ga}_{2} \mathrm{O}_{3}$ crystal.

The transfer curve with the drain current density, $I_{\mathrm{d}}$, in both $\log$-scale and linear-scale, of the $\mathrm{Ga}_{2} \mathrm{O}_{3}$ FET photodetector in dark is shown in Fig. 3(a). The drain voltage, $V_{\mathrm{d}}$, was kept at 20 $\mathrm{V}$ during the measurement. The on/off current ratio of the FET is about $2.3 \times 10^{6}$. The threshold voltage is about $-7 \mathrm{~V}$, as extracted from the linear extrapolation of the transfer curve in linear scale. The subthreshold threshold, $S S$, is about $0.63 \mathrm{~V} / \mathrm{dec}$, as extracted from the linear extrapolation of the transfer curve in $\log$ scale. The channel trap density $D_{\mathrm{t}}$ is extracted by evaluation of $S S$ as follows [25]:

$$
S S=\frac{\mathbf{k}_{B} T}{e}\left(1+\frac{q^{2} D_{t}}{C_{O X}}\right) \ln 10
$$

where $q$ is the electron charge, $k_{\mathrm{B}}$ is the Boltzmann constant, $T$ is the absolute temperature, and $C_{\mathrm{ox}}$ is the gate capacitance per unit area. By Eq. (1), $D_{\mathrm{t}}$ is determined to be $2.06 \times 10^{12} \mathrm{~cm}^{-2}$, and is larger than those of reported $\mathrm{Ga}_{2} \mathrm{O}_{3}$ FETs $\left(\sim 10^{11} \mathrm{~cm}^{-2}\right)$ $[16,26]$. The high $D_{\mathrm{t}}$ leads to the relative high threshold voltage [27]. Figure 3(b) shows the output curves of the FET. The gate bias $\left(V_{\mathrm{g}}\right)$ varied from -14 to $10 \mathrm{~V}$ with a step of $4 \mathrm{~V}$. It reveals a typical transistor performance with that $I_{\mathrm{d}}$ increased linearly at low $V_{\mathrm{d}}$ and saturated at high $V_{\mathrm{d}}$ with increased $V_{\text {d. }}$. The output curves show clear saturation and pinch-off characteristics, indicating effective gate modulations in the n-type channel.

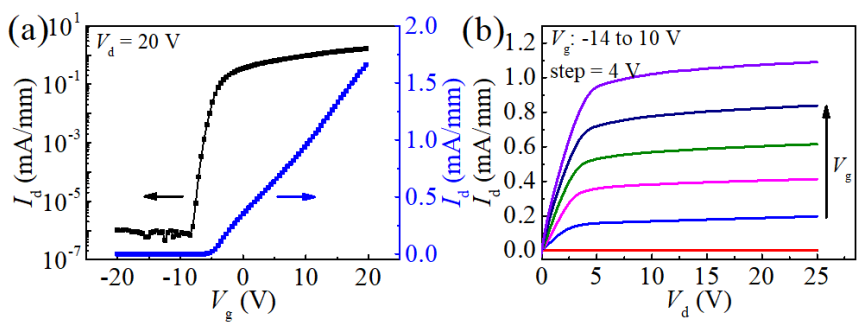

Fig. 3. Typical electrical transport properties of the $\mathrm{Ga}_{2} \mathrm{O}_{3}$ FET. (a) The transfer curve in $\log$ and linear scale with $V_{\mathrm{d}}$ of $20 \mathrm{~V}$, (b) The output curves with various $V_{\mathrm{g}}$ (from -14 to $10 \mathrm{~V}$ ).

Figure 4 exhibits the photo response properties of the $\mathrm{Ga}_{2} \mathrm{O}_{3}$ FET photodetector with UV light on and off. All these characterizations were carried at a pinch-off $V_{\mathrm{g}}$ of $-20 \mathrm{~V}$, and the drain current with light on and off is defined as $I_{\text {photo }}$ and $I_{\text {dark, }}$, respectively. The dependences of the drain current on light at different $V_{\mathrm{d}}$ are shown in Fig. 4(a). The drain current zooms 
along with the light on and drops rapidly in pace with the light off at all $V_{\text {d. }}$. Figure $4\left(\right.$ b) shows $I_{\text {photo }}$ and $I_{\text {photo }} / I_{\text {dark }}$ as functions of $V_{\text {d. }} I_{\text {photo }}$ increases almost linearly with the increase of $V_{\mathrm{d}}$. Figure 4 (b) shows almost linear dependences of $I_{\text {photo }}$ and $I_{\text {photo }} / I_{\text {dark }}$ on $V_{\text {d, demonstrating that }} I_{\text {photo }}$ and $I_{\text {photo }} / I_{\text {dark }}$ of the $\mathrm{Ga}_{2} \mathrm{O}_{3}$ FET photodetector can be tuned linearly by $V_{\text {d }}$. Here, for evaluating $I_{\text {photo }} / I_{\text {dark }}$ the same $I_{\text {dark }}$ values of $5 \times 10^{-12} \mathrm{~A}$ at various $V_{\mathrm{d}}$ was used, as $10^{-12} \mathrm{~A}$ already reaches our detection limit.
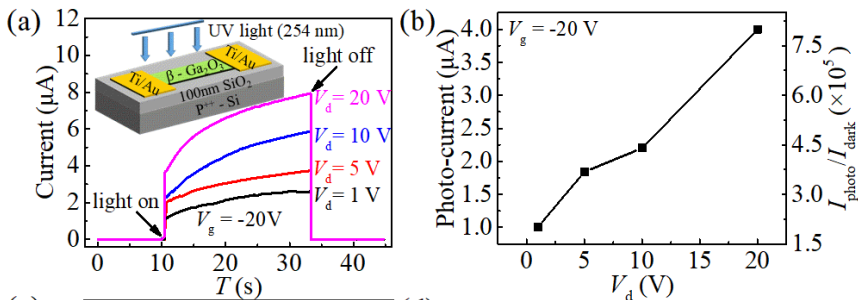

(c)
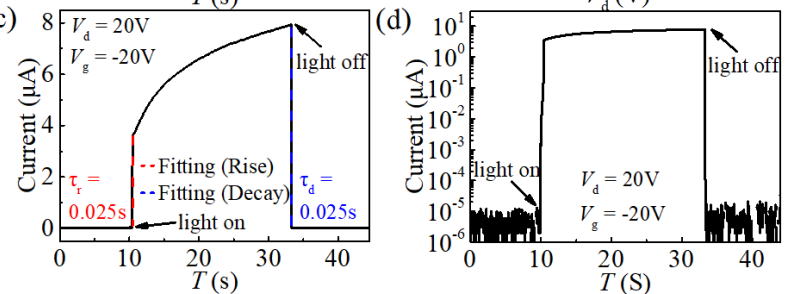

Fig. 4. (a) The current dependences of the $\mathrm{Ga}_{2} \mathrm{O}_{3}$ FET solar-blind photodetector on time with the light switching at different $V_{\mathrm{d}}$, (b) $I_{\text {photo }}$ and $I_{\text {photo }} / I_{\text {dark }}$ as functions of $V_{\mathrm{d}}$. (c) The linear-scale current dependence on time with the light switching at $V_{\mathrm{d}}$ of $20 \mathrm{~V}$ with fittings of current rise and decay process, (d) The log-scale current dependence on time with the light switching at $V_{\mathrm{d}}$ of $20 \mathrm{~V}$

TABLE I

Summary Of Key Photoresponse Parameters Of The Fet Solar-Blind PHOTODETECTOR

\begin{tabular}{cc}
\hline \hline Parameters & Data \\
\hline Photo-current $\left(I_{\text {photo }}\right)[\mu \mathrm{A}]$ & 7.93 \\
Response time $\tau_{r} / \tau_{d}[\mathrm{~s}]$ & $0.025 / 0.025$ \\
$I_{\text {photo }} / I_{\text {dark }}$ & $8 \times 10^{5}$ \\
Responsivity $(R)[\mathrm{A} / \mathrm{W}]$ & $4.79 \times 10^{5}$ \\
Detectivity $\left(D^{*}\right)[\mathrm{Jones}]$ & $6.69 \times 10^{14}$ \\
EQE [\%] & $2.34 \times 10^{6}$ \\
\hline \hline
\end{tabular}

The photodetector shows the highest $I_{\text {photo }} / I_{\text {dark }}$ with $V_{\mathrm{d}}$ of 20 $\mathrm{V}$, as shown in Fig. 4(a). With $V_{\mathrm{d}}$ of $20 \mathrm{~V}, I_{\text {photo }}$ of the photodetector suddenly increased to $4 \mu \mathrm{A}$ when the light turned on and increased further slowly with prolonged irradiation. Both rise time, $\tau_{r}$, and decay time, $\tau_{d}$, are about $25 \mathrm{~ms}$ by fittings [28], as shown in Fig. 4(c), and is lower than the reported values [17]. The reasons could be that the gate operation voltage applied on our $\mathrm{Ga}_{2} \mathrm{O}_{3}$ photodetector is much lower than its threshold voltage. It should be clarified that $25 \mathrm{~ms}$ is the shortest time step value of our source measurement unit under normal mode we used. Thus, the real $\tau_{\mathrm{r}}$ and $\tau_{\mathrm{d}}$ should be $\leq 25 \mathrm{~ms}$. Figure 4(d) shows $I_{\text {photo }}$ in $\log$-scale with $V_{\mathrm{d}}$ of $20 \mathrm{~V}$, illustrating a high $I_{\text {photo }} / I_{\text {dark }}$ of $8 \times 10^{5}$. The strong generation of electron-hole pairs under the light irradiation and the low dark current $\sim 10^{-12}$ A contribute to such high $I_{\text {photo }} / I_{\text {dark. }}$. It should be noticed that after tuning off the light, the current dropped rapidly back to $10^{-12} \mathrm{~A}$, which is the noise floor of our measurement system. This is extremely beneficial for continuous and solar blind UV detection with high $I_{\text {photo }} / I_{\text {dark }}$ and low interference. The results reveal that the $\mathrm{Ga}_{2} \mathrm{O}_{3}$ FET solar-blind photodetector can achieve high $I_{\text {photo }} / I_{\text {dark }}$ ratio and quick response.

The responsivity, $R$, detectivity, $D^{*}$, and external quantum efficiency, EQE, are the other key parameters to evaluate the performances of photodetectors. $R$ and EQE evaluate the sensitivity of photodetectors [29], while $D^{*}$ indicates the capability of photodetectors to detect small signals. $R$, was estimated to be $4.79 \times 10^{5} \mathrm{~A} / \mathrm{W}$ using the equation $R=\left(I_{\text {photo }}-I_{\text {dark }}\right) / S \cdot P$ inc $[30,31]$, where $S$ is the effective area of the channel, and $P_{\text {inc }}$ is the illumination power. Besides, because the shot noise from the dark current dominates the total noise, $D^{*}$ can be calculated by the equation $D^{*}=R \cdot S^{0.5} /(2 e I \text { dark })^{0.5}[30$, 31], where $e$ is the elementary charge. $D^{*}$ of our device is $\sim 6.69$ $\times 10^{14}$, and is comparable to the reported value for $\mathrm{Ga}_{2} \mathrm{O}_{3}$ FET solar-blind photodetector. And it also exhibits a high EQE of $2.34 \times 10^{6}$, estimated by the equation $\mathrm{EQE}=h c R /(e \lambda)[32]$, where $h$ and $c$ are the Planck's constant and velocity of light, respectively. The photoresponse properties of the fabricated solar-blind photodetector are summarized in Table I.

\section{CONCLUSION}

FET solar-blind photodetectors have been fabricated based on high quality quasi-two-dimensional single crystalline $\mathrm{Ga}_{2} \mathrm{O}_{3}$ flakes exfoliated from the bulk single crystal. The $\mathrm{Ga}_{2} \mathrm{O}_{3}$ FET show excellent photo response in the pinched off gate modulation state, with $I_{\text {photo }}$ improves rapidly as the UV light on and drops down quickly as the UV light off. $I_{\text {photo }}$ and $I_{\text {photo }} / I_{\text {dark }}$ of the photodetector can be tuned by the drain voltage. High $I_{\text {photo }} / I_{\text {dark }}$ of $8 \times 10^{5}$, responsivity of $4.79 \times 10^{5} \mathrm{~A} / \mathrm{W}, \mathrm{EQE}$ of $2.34 \times 10^{6}$, and quick response with $I_{\text {photo }}$ rise and decay time of $25 \mathrm{~ms}$ were realized, indicating huge potential in solar-blind photodetector application field.

\section{REFERENCES}

[1] X. Chen, Y. Xu, D. Zhou, S. Yang, F. Ren, H. Lu, K. Tang, S. Gu, R. Zhang, Y. Zheng, and J. Ye, "Solar-blind photodetector with high avalanche gains and bias-tunable detecting functionality based on metastable phase $\alpha-\mathrm{Ga}_{2} \mathrm{O}_{3} / \mathrm{ZnO}$ isotype heterostructures," $A C S$ Appl. Mater. Inter., vol. 9, no. 42, pp. 36997-37005, Oct. 2017, doi: 10.1021/acsami.7b09812.

[2] L. Li, E. Auer, M. Liao, X. Fang, T. Zhai, U.K. Gautam, A. Lugstein, Y. Koide, Y. Bando, and D. Golberg, "Deep-ultraviolet solar-blind photoconductivity of individual gallium oxide nanobelts," Nanoscale, vol. 3, no. 3, pp. 1120-1126, Jan. 2011, doi: 10.1039/C0NR00702A.

[3] S. Assefa, F. Xia, and Y.A. Vlasov, "Reinventing germanium avalanche photodetector for nanophotonic on-chip optical interconnects," Nature, vol. 464, no. 7285, pp. 80-84, Mar. 2010, doi: 10.1038/nature0881380.

[4] Y. Chen, Y. Lu, C. Lin, Y. Tian, C. Gao, L. Dong, and C. Shan, "Selfpowered diamond $/ \mathrm{\beta}-\mathrm{Ga}_{2} \mathrm{O}_{3}$ photodetectors for solar-blind imaging," $J$. Mater. Chem. C., vol. 6, pp. 5727-5732, May 2018, doi: 10.1039/c8tc01122b.

[5] P. Fan, U.K. Chettiar, L. Cao, F. Afshinmanesh, N. Engheta, and M.L. Brongersma, "An invisible metal-semiconductor photodetector," Nature Photon., vol. 6, no. 6, pp. 380-385, May 2012, doi: 10.1038/NPHOTON.2012.108.

[6] E.A. Azhar, J. Vanjaria, S. Ahn, T. Fou, S.K. Dey, T. Salagaj, N. Sbrockey, G.S. Tompa, and H. Yu, "Vapor-transport synthesis and annealing study of $\mathrm{Zn}_{\mathrm{x}} \mathrm{Mg}_{1-\mathrm{x}} \mathrm{O}$ nanowire arrays for selective, solar-blind UV-C detection," ACS Omega, vol. 3, no. 5, pp. 4899-4907, May 2018, doi: 10.1021/acsomega.7b01362.

[7] Q. Cai, M. Ge, J. Xue, L. Hu, D. Chen, H. Lu, R. Zhang, and Y. Zheng, "An improved design for solar-blind AlGaN avalanche photodiodes," 
IEEE Photonics J., vol. 9, no. 4, pp. 1-7, Jul. 2017, doi: 10.1109/JPHOT.2017.2725305.

[8] H. Aida, K. Nishiguchi, H. Takeda, N. Aota, K. Sunakawa, and Y. Yaguchi, "Growth of $\beta-\mathrm{Ga}_{2} \mathrm{O}_{3}$ single crystals by the edge-defined, film fed growth method," Jap. J. Appl. Phys., vol. 47, no. 11R, pp. 8506-8509, Nov. 2008, doi: 10.1143/JJAP.47.8506.

[9] W. Mu, Z. Jia, Y. Y in, Q. Hu, Y. Li, B. Wu, J. Zhang, and X. Tao, "High quality crystal growth and anisotropic physical characterization of $\beta$ $\mathrm{Ga}_{2} \mathrm{O}_{3}$ single crystals grown by EFG method," J. Alloys Compd., vol. 714, pp. 453-458, Nov. 2017, doi: 10.1016/j.jallcom.2017.04.185.

[10] H. Chen, P. Yu, Z. Zhang, F. Teng, L. Zheng, K. Hu, X. Fang, "Ultrasensitive self-powered solar-blind deep-ultraviolet photodetector based on all-solid-state polyaniline/MgZnO bilayer," Small, vol. 12, no. 42, pp. 5809-5816, Sept. 2016, doi: 10.1002/smll.201601913.

[11] S. Oh, Y. Jung, M.A. Mastro, J.K. Hite, C.R. Eddy, and J. Kim, "Development of solar-blind photodetectors based on Si-implanted $\beta$ $\mathrm{Ga}_{2} \mathrm{O}_{3}$," Opt. Express, vol. 23, no. 22, pp. 28300-5, Oct. 2015, doi: 10.1364/OE.23.028300.

[12] D.Guo, Z. Wu, P. Li, Y. An, H. Liu, X. Guo, H. Yan, G. Wang, C. Sun, and $\mathrm{L} . \mathrm{Li}$, "Fabrication of $\beta-\mathrm{Ga}_{2} \mathrm{O}_{3}$ thin films and solar-blind photodetectors by laser MBE technology," Opt. Mater. Express, vol. 4, no. 5, pp. 1067-1076, May 2014, doi: 10.1364/OME.4.001067.

[13] Z.Wu, G. Bai, Y. Qu, D. Guo, L. Li, P. Li, J. Hao, and W. Tang, "Deep ultraviolet photoconductive and near-infrared luminescence properties of $\mathrm{Er}^{3+}$-doped $\beta-\mathrm{Ga}_{2} \mathrm{O}_{3}$ thin films," Appl. Phy. Lett., vol. 108, no. 21, pp. 380-385, May 2016, doi: 10.1063/1.4952618.

[14] D. Guo, H. Liu, P. Li, Z. Wu, S. Wang, C. Cui, C. Li, and W. Tang, "Zero-power-consumption solar-blind photodetector based on $\beta$ $\mathrm{Ga}_{2} \mathrm{O}_{3}$ /NSTO heterojunction," ACS Appl. Mater. Inter., vol. 9, no. 2, pp. 1619, Dec. 2017, doi: 10.1021/acsami.6b13771.

[15] W. Mu, Z. Jia, Y. Yin, Q. Hu, J. Zhang, Q. Feng, Y. Hao, and X. Tao, "One-step exfoliation of ultra-smooth $\beta-\mathrm{Ga}_{2} \mathrm{O}_{3}$ wafers from bulk crystal for photodetectors," Crystengcomm, vol. 19, no. 34, pp. 5122-5127, Aug. 2017, doi: 10.1039/c7ce01076a

[16] H. Zhou, M. Si, S. Alghamdi, G. Qiu, L. Yang, P. D. Ye, "Highperformance depletion/enhancement-mode $\beta-\mathrm{Ga}_{2} \mathrm{O}_{3}$ on insulator (GOOI) field-effect transistors with record drain currents of $600 / 450 \mathrm{~mA} / \mathrm{mm}$ ", IEEE Elec. Dev. Lett., 2017, vol. 38, no. 1, pp. 103-106, Dec. 2016, doi: 10.1109/LED.2016.2635579.

[17] S. Oh, J. Kim, F. Ren, S.J. Pearton, and J. Kim, "Quasi-two-dimensional $\beta$-gallium oxide solar-blind photodetectors with ultrahigh responsivity," J. Mater. Chem. C, vol. 4, no. 39, pp. 9245-9250, Sept. 2016, doi: 10.1039/C6TC02467J.

[18] K. Yamaguchi, "First principles study on electronic structure of $\beta$ $\mathrm{Ga}_{2} \mathrm{O}_{3}$," Solid State Commun., vol. 131, no. 12, pp. 739-744, Sept. 2004, doi: 10.1016/j.ssc.2004.07.030.

[19] G. Shin, H.-Y. Kim, and J. Kim, "Deep-ultraviolet photodetector based on exfoliated n-type $\beta-\mathrm{Ga}_{2} \mathrm{O}_{3}$ nanobelt $/ \mathrm{p}$-Si substrate heterojunction," $J$. of Chem. Eng., vol. 35, no. 2, pp. 574-578, Dec. 2018, doi: 10.1007/s11814-017-0279-7.

[20] X. Zhao, Z. Wu, Y. Zhi, Y. An, W. Cui, L. Li, and W. Tang, "Improvement for the performance of solar-blind photodetector based on $\beta-\mathrm{Ga}_{2} \mathrm{O}_{3}$ thin films by doping Zn," J. Phys. D: Appl. Phys., vol. 50, no. 8, pp. 085102-1--085102-6. Jan. 2017, doi: 10.1088/1361-6463/aa5758J.

[21] C. Yang, H. Liang, Z. Zhang, X. Xia, P. Tao, Y. Chen, H.Q. Zhang, R. Shen, Y. Luo, and G. Du, "Self-powered SBD solar-blind photodetector fabricated on the single crystal of $\beta-\mathrm{Ga}_{2} \mathrm{O}_{3}$," Rsc $A d v$., vol. 8, no. 12, pp. 6341-6345, Feb. 2018, doi: 10.1039/C8RA00523K.

[22] M. Ai, D. Guo, Y. Qu, W. Cui, Z. Wu, P. Li, L. Li, and W. Tang, "Fastresponse solar-blind ultraviolet photodetector with a graphene $/ \beta-\mathrm{Ga}_{2} \mathrm{O}_{3}$ /graphene hybrid structure," J. Alloys Compd., vol. 692, no. 25, pp. 634638, Jan. 2017, doi: 10.1016/j.jallcom.2016.09.087.

[23] W. Kim, K. S. Chu, "ZnO nanowire field - effect transistor as a UV photodetector; optimization for maximum sensitivity," Phys. Status Solidi. A, vol. 206, no. 1, pp. 179-182, Oct. 2008, doi: $10.1002 /$ pssa.200824338.

[24] Z. Galazka, S. Ganschow, A. Fiedler, R. Bertram, D.Klimm, K. Irmscher, R. Schewski, M. Pietsch, M. Albrecht, M. Bickermann, "Doping of Czochralski-grown bulk $\beta-\mathrm{Ga}_{2} \mathrm{O}_{3}$, single crystals with $\mathrm{Cr}$, Ce and Al", $J$. Cryst. Growth., vol. 486, pp. 82-90, Mar. 2018, doi: 10.1016/j.jcrysgro.2018.01.022.

[25] B. Zhang, H. Li, X. Zhang, Y. Luo, Q. Wang, A. Song, "Performance regeneration of InGaZnO transistors with ultrathin channels", Appl. Phys. Lett., vol. 106, pp. 093506, Mar. 2015, doi: 10.1063/1.4914296.

[26] J. Kim, M. A. Mastro, M. J. Tadjer, J. Kim, "Quasi-Two-Dimensional h
- BN $/ \beta-\mathrm{Ga}_{2} \mathrm{O}_{3}$ Heterostructure Metal-Insulator-Semiconductor FieldEffect Transistor", ACS Appl. Mater. Interfaces, vol. 9, pp. 21322-21327, May 2017, doi: 10.1021/acsami.7b04374.

[27] S. Y. Lee, D. Kim, E. Chong, Y. W. Jeon, D. H. Kim, "Effect of channel thickness on density of states in amorphous InGaZnO thin film transistor", Appl. Phys. Lett., vol. 98, no. 12, pp. 12205, Mar. 2011, doi: 10.1063/1.3570641.

[28] S. Cui, Z. Mei, Y. Zhang, H. Liang, X. Du, "Room-temperature fabricated amorphous $\mathrm{Ga}_{2} \mathrm{O}_{3}$ high-response-speed solar-blind photodetector on rigid and flexible substrates," Adv. Opt. Mater. Vol. 5, no. 19, pp. 1700454-1-9, Jul. 2017, doi: 10.1002/adom.201700454.

[29] M. Zhong, Z. Wei, X. Meng, F. Wu, J. Li, "High-performance single crystalline UV photodetectors of $\beta-\mathrm{Ga}_{2} \mathrm{O}_{3}$," J. Alloys Compd., vol. 619, pp. 572-575, Jan. 2015, doi: 10.1016/j.jallcom.2014.09.070.

[30] W.Y. Kong, G.A. Wu, K.Y. Wang, T.F. Zhang, Y.F. Zou, D.D. Wang, L.B. Luo, "Graphene- $\beta-\mathrm{Ga}_{2} \mathrm{O}_{3}$ heterojunction for highly sensitive deep UV photodetector application," Adv. Mater. vol. 28, no. 48, pp. 10725-10731, Oct. 2016, doi: 10.1002/adma.201604049.

[31] T.C. Wei, D.S. Tsai, P. Ravadgar, J.J. Ke, M.L.Tsai, D.H. Lien, C.Y. Huang, R.H. Horng, and Jr.H. He, "See-through $\mathrm{Ga}_{2} \mathrm{O}_{3}$ solar-blind photodetectors for use in harsh environments," IEEE J. Sel. Top Quant., vol. 20, no. 6, pp. 112-117, May 2014, doi: 10.1109/JSTQE.2014.2321517.

[32] R. Zou, Z. Zhang, Q. Liu, J. Hu, L. Sang, M. Liao, and W. Zhang, "High detectivity solar - blind high - temperature deep - ultraviolet photodetector based on multi - layered (100) facet - oriented $\beta-\mathrm{Ga}_{2} \mathrm{O}_{3}$ nanobelts," Small, vol. 10, no. 9, pp. 1848-1856, Feb. 2014, doi: 10.1002/smll.201302705. 